\title{
Despoblación en Navarra, nuevas oportunidades desde la economía social y solidaria y feminista
}

\author{
Depopulation in Navarre, New Opportunities From Social \\ and Solidarity and Feminist Economics \\ Izaskun BARBA Areso*
}

\begin{abstract}
Resumen: Más de la mitad de toda la población de la Comunidad Foral Navarra tiene como epicentro la capital, Pamplona, y su cuenca. Cada vez menos gente elige vivir en las áreas rurales y éstas se están despoblando. Este fenómeno migratorio tiene sesgo de género. La desigual carga de cuidados y las dificultades que presenta vivir en ciertas zonas de Navarra de cara a la obtención de empleo y de servicios básicos hace que cada vez sea menor la proporción de mujeres jóvenes que viven en pueblos navarros. La economía social y solidaria se presenta como una herramienta de cambio y una oportunidad para la re-ruralización. También como garantía de una vida buena en zonas rurales.
\end{abstract}

Palabras clave: Despoblación Rural, Género, Economía Social y Solidaria, Economía Feminista, Emprendimiento, Políticas Públicas, Economía Regional, Demografía.

Abstract: More than half of the entire population of the region of Navarra is concentrated in the capital city, Pamplona, and its basin. Fewer and fewer people are choosing to live in rural areas and these are becoming depopulated. This migratory phenomenon has a gender bias. The unequal burden of care and the difficulties of living in certain areas of Navarra in terms of lack of employment opportunities and basic services mean that the proportion of young women living in Navarre's villages is decreasing. The social and solidarity economy is presented as a tool for change and an opportunity for re-ruralization. Also as a guarantee of good living-standards in rural areas.

Keywords: Rural Depopulation, Gender, Social and Solidarity Economy, Feminist Economics, Entrepreneurship, Public Policies, Regional Economics, Demographics.

Códigos Econlit: B54; B55; R11

* Correspondencia a/Corresponding author: Izaskun Barba Areso - izaskunbarba@hotmail.com - https://orcid.org/ 00000003-2633-882X

Cómo citar/How to cite: Barba Areso, Izaskun (2021). "Despoblación en Navarra, nuevas oportunidades desde la economía social y solidaria y feminista", GIZAEKOA - Revista Vasca de Economía Social, 18, 157-190. (https://doi.org/10.1387/gizaekoa.22905).

Recibido: 28/05/2021; aceptado: 10/06/2021.

ISSN 1698-7446 - elSSN 2444-3107 / (C) 2021 UPV/EHU

(c) Esta obra está bajo una licencia

Creative Commons Atribución 4.0 Internacional 


\section{Introducción}

El mundo rural es vital, por un lado, por su labor productiva y, por otro lado, por las diversas funciones que realiza. Entras otras, por su carácter social, manteniendo la vida de las familias en el entorno rural. Segundo, por su labor cultural, manteniendo y asegurando la transmisión oral de la cultura entre generaciones, el patrimonio de los pueblos y el de la cultura gastronómica de los territorios. Y también por su función medioambiental, manteniendo vivo el paisaje y conservando los recursos naturales además de preocuparse por el entorno (Fernández, 2002).

Sin embargo, en las últimas décadas, se ha dado un proceso de despoblación generalizado, dejando vacíos pueblos y zonas rurales que antes eran el centro de la vida y del trabajo de muchas personas. El sistema económico en el que vivimos insta cada vez más a la industrialización y a los servicios, dejando de lado a un primer sector que ha visto cómo su actividad se reduce y su trabajo se centra en cada vez menos manos. Sin embargo, ya en 1983, la Carta Europea de Ordenación del Territorio ${ }^{1}$ dictó como objetivos principales el desarrollo socioeconómico equilibrado de las regiones, la mejora de la calidad de vida, la gestión responsable de los recursos naturales y la protección del medio ambiente, así como la utilización racional del territorio. Es algo evidente hoy en día, que las regiones han tenido un desarrollo socioeconómico desequilibrado y se ha hecho un uso irresponsable de los recursos naturales. La misma carta defiende que es «indispensable crear condiciones de vida equivalentes entre ciudad y campo tanto a nivel económico, social, cultural y ecológico».

Esto difiere mucho de la realidad que se está viviendo de forma generalizada hoy en día, y como ejemplo claro podemos poner a Navarra. Según el Observatorio de Realidad Social en su informe sobre Desigualdades Territoriales en Navarra ${ }^{2}$ de inicio del 2020, más de la mitad de toda la población de la Comunidad Foral tiene como epicentro Pamplona y su cuenca. Cada vez menos gente elige vivir en las áreas rurales y gran parte de la población está migrando a Pamplona y sus alrededores. De hecho, la zona de los Pirineos, una de las más alejadas de núcleos urbanos, ha sido la más afectada.

Según el citado informe del Gobierno de Navarra, la despoblación tiene sesgo de género y cada vez viven menos mujeres en las zonas rurales. En efecto, en la mayoría de municipios rurales la masculinización se da en

${ }^{1}$ Consejo de Europa (1983) Carta Europea de Ordenación al Territorio. Disponible en: https://www.uco.es/-gt1 tomam/master/ot/cartaeuropea1983.pdf

2 Observatorio de la Realidad Social Navarra (2020) Desigualdades Territoriales en Navarra. Disponible en: https://bit.ly/2UpyeQG 
las edades jóvenes e intermedias, debido, señalan, principalmente a la importante emigración femenina en esas edades, dada por la falta de igualdad en el trabajo productivo y reproductivo.

Desde el punto de vista de la Administración, se están haciendo esfuerzos por analizar la gravedad de la situación e impulsar el retorno al ámbito rural. En la nueva legislatura que empezó en 2019, se creó, bajo el departamento de Cohesión Territorial, la dirección general de Administración Local y Despoblación, para tratar el tema. Los medios de comunicación también están dando voz al fenómeno. Se habla de población envejecida, de inmigración poco integrada, de sectores no modernizados, y aunque se habla de procesos de masculinización en algunas zonas, no habla poco de la perspectiva de género en la despoblación.

Esta investigación analiza la despoblación con perspectiva de género en Navarra y tratará de señalar cuáles son algunas de las fórmulas que están funcionando para hacer frente a la migración campo-ciudad de las mujeres en la comunidad Foral. Estas nuevas experiencias siguen los principios de la economía solidaria, ecológica y feminista.

La estructura del trabajo consta de 7 apartados. Comienza con los vínculos entre la economía solidaria, feminista y la ecológica. Después se habla de las migraciones y su relación con el género. Más tarde se realiza un análisis del estado de despoblación de Navarra, para intentar dar una explicación a la feminización del fenómeno de la despoblación. Una vez explicada la teoría, se procede con el análisis de los resultados de las entrevistas personales a mujeres y se intenta identificar qué se podría aportar a las políticas públicas de desarrollo rural. Finalmente, conclusiones, anexos y bibliografía.

\section{Vínculos entre la economía solidaria, ecológica, feminista y la lucha contra la despoblación}

El sistema capitalista sitúa lo mercantil como el centro de las actividades económicas y clasifica como no económicas todas aquellas no remuneradas que trabajan por la sostenibilidad de la vida, empleando como justificación que son difícilmente cuantificables y fácilmente excluibles (Jubeto, y Larrañaga, 2014). Paradójicamente, en el espacio mercantil, que es donde se anula la importancia de la solidaridad y el cuidado de la vida, es también donde se organiza el tiempo y el territorio; se decide cómo intervenir en la naturaleza, se elige qué se investiga, se pone y quita gobernantes (Herrero, 2013).

Al mismo tiempo, la explotación en el trabajo remunerado del mercado supone un medio de acumulación y la participación en el mismo sirve de vía para obtener derechos sociales y económicos (Herrero, 2013) ya que to- 
das aquellas personas excluidas del trabajo remunerado se quedan sin derechos por sí mismas. Como consecuencia, mujeres que no tienen un trabajo remunerado y se han dedicado a las labores del hogar, no tienen por sí mismas derechos económicos y ciudadanos.

Pérez Orozco (2006) sostiene que, además, existe una marcada segregación ocupacional. Tal y como lo recoge la autora,

en casi todas las sociedades, existe una división del trabajo por género tanto en el trabajo remunerado como en el no remunerado (...) aunque la naturaleza del trabajo especializado realizado por mujeres y hombres difiere sustancialmente según lugar, tiempo y, en algunos casos, a lo largo del ciclo vital.

El trabajo doméstico tiene una sustancial consecuencia en el mercado de trabajo remunerado después (Carrasco, 2014). La autora defiende que la responsabilidad del trabajo doméstico que recae en las mujeres les impide estar en igualdad de condiciones que los hombres de cara al trabajo de mercado. Es por esto que las mujeres tienden a tener mayor carga de trabajo, problemas de organización del tiempo, salarios más bajos... La autora lo define como una pobreza específica de las mujeres.

$\mathrm{Al}$ igual que pasa con el trabajo de cuidados, la importancia de la naturaleza no se contabiliza. Según Orozco (2006), el capitalismo y el patriarcado son dos sistemas de poder, poderosos e históricamente ligados y su coexistencia explica la opresión de la mujer y la naturaleza. De hecho, las actuales condiciones de funcionamiento del sistema económico son totalmente insostenibles para la naturaleza (Carrasco, 2014). La autora señala que la crisis ecológica que estamos viviendo está relacionada con el agotamiento de recursos, diversas formas de contaminación, cambio climático y pérdida de biodiversidad, pero también con graves problemas de desigualdad, pobreza y con nuevas formas de empobrecimiento que han surgido por la propia degradación ambiental.

Esta perspectiva concuerda con el aspecto no monetarizable de la despoblación. La vida rural parece no tener valor de no ser porque su inactividad produzca pérdidas. Según Herrero (2014) la economía convencional y su lógica es la que toma las decisiones sobre ordenación del territorio. La autora defiende que esto no tiene ningún sentido si no tienen como objetivo principal, en primer lugar, identificar correctamente, y luego, satisfacer las necesidades humanas y de la naturaleza. En efecto, Chulvi (1999) observa en las zonas rurales carencias en la provisión de servicios básicos como escuelas infantiles, educación, asistencia sanitaria, servicios asistenciales y centros culturales.

En cambio, la economía solidaria, pone el foco en lo que no pasa por el mercado. «La economía social y solidaria (ESS) ha sido invocada para 
dar respuestas a las necesidades que no pueden ser satisfechas por el mercado ni por el Estado» (Salazar, 2014). A su vez, defiende que para la generación y gestión del bienestar social se necesita también el conjunto de hogares, estado y comunidad (Álvarez, 2010). La ESS es una articulación social necesaria, ya que como explica Herrero (2014), el capitalismo y la ideología neoliberal dan la espalda a las dependencias del ser humano hacia los cuidados y la naturaleza e ignoran los límites que ponen a la sociedad. Carrasco (2014) coincide con ella y menciona que la relación que tienen con la naturaleza «la economía capitalista, la sociedad patrarcal y una cultura tecnológica androcéntrica son las responsables de los crecientes problemas ecológicos locales y globales». Esta corriente considera, que la economía es inseparable de la ética, la cultura y la política (Arias, y Cid, 2019). Bajo este paraguas de Economía Solidaria, se contemplan algunos de los movimientos políticos que luchan por la defensa de las personas y el territorio.

Las autoras Jubeto y Larrańaga (2014) sostienen que una de las características de la economía solidaria es su compromiso con el entorno, dependiendo de los hogares, comunidades y la memoria histórica de los territorios. En efecto, la economía social la componen organizaciones eficaces para el aprovechamiento de las nuevas oportunidades de empleo que promueven el desarrollo regional y local, contribuyendo a diversificar la economía rural y a generar trabajo y renta, frenando así el retroceso demográfico (Gómez, y Rico, 2011).

Pérez Orozco (2006) explica que la Economía Feminista (EF) pone en duda la normatividad de los términos androcéntricos. Reconoce el valor de los trabajos de las mujeres en el sistema económico, pero saliéndose de la lógica del mercado, buscando nuevas herramientas y conceptos que intentan explicar las experiencias femeninas. La economía solidaria defiende, igual que lo hace la economía feminista, las relaciones basadas en la interdependencia y la equidad, y ambas reconocen el valor de los trabajos domésticos y de cuidados que realizan las mujeres, que han sido sistemáticamente invisibilizados (Jubeto, y Larrańaga, 2014). Analizando los vínculos entre la EF y la solidaria, cabe resaltar que

el análisis económico feminista ha observado la organización del trabajo familiar en relación a la satisfacción colectiva de necesidades, mientras las premisas de la economía solidaria llevan esta pregunta a escala comunal y societal, donde el trabajo se reparte a través de las jerarquias sociales y del género. (Arias, y Cid, 2019)

De hecho, una gran parte de las políticas públicas de los gobiernos para reducir la desigualdad entre hombres y mujeres, están relacionadas con los 
principios y los valores de la economía solidaria, teniendo como base una participación igualitaria, solidaria y demócrata (Gómez, y Rico, 2011).

Otra de sus características es la búsqueda de relaciones equitativas, democráticas y horizontales, que tengan como objetivo priorizar las necesidades humanas sin ánimo de lucro (Jubeto, y Larrañaga, 2014). La economía social propone las cooperativas como elemento de transformación socioeconómica y agente de cambio en los territorios (Mozas, y Bernal, 2006). Las cooperativas se consideran una herramienta inagotable con capacidad de crear empresas especialmente en zonas rurales en despoblación, impulsando el empleo, el bienestar y el desarrollo local (Mozas, y Bernal, 2006).

Tal y como marcan Jubeto y Larrañaga, la economía solidaria también comparte puntos de vista con la ecológica, defendiendo que a la vez que seres interdependientes, somos seres ecodependientes. Además, entre sus principios están la sostenibilidad ambiental y el compromiso con el entorno. Según estas corrientes la economía debería centrarse en la manera sostenible de, respetando los límites y los tiempos de la naturaleza, contribuir al desarrollo personal, social y ambiental de la humanidad (Jubeto, y Larrañaga, 2014). De esta manera, se entrelazan la economía solidaria, la feminista y la ecológica.

Bosch, Carrasco y Grau (2005) plantean la necesidad de una sostenibilidad humana, social y ecológica, y lo definen como proceso que no solo habla de la posibilidad de que la vida continúe, sino a que además se asegure de desarrollar niveles de vida, estándares de vida o calidad de vida aceptables para toda la población.

El objetivo principal de esta investigación es analizar cómo influyen las iniciativas desarrolladas por mujeres dentro de la Economía Solidaria para hacer frente a los actuales procesos de despoblación de Navarra.

\section{Migraciones, género y desigualdades mundo rural}

\subsection{Migraciones y desigualdades}

Según Pérez Díaz (1971) la jerarquía social marca la disposición a migrar, y la presión estructural «se reparte desigualmente sobre la población, afectando con mayor o menor intensidad a unos y otros, según sus diversos atributos de posición en el sistema social». La migración de las mujeres es una realidad que ha estado presente en todas las épocas de la historia, sin embargo, ha sido invisibilizada hasta entrado el siglo xx (Magliano, 2009). Como dice Yayo Herrero (2020), las primeras migrantes fueron las mujeres de los pueblos que se iban a la ciudad a servir en casas de familias ricas. 
En el caso de la migración rural-urbana, las desigualdades entre campo y ciudad vienen de una serie de procesos socioeconómicos y/o políticoinstitucionales. Desde mediados del siglo xx y de manera más exponencial en los últimos años, las zonas rurales se están despoblando (Camarero y Sampedro, 2008). Aunque la desigualdad es una constante geográfica e histórica, sí son diferentes las oportunidades y los medios para hacer frente a esa desigualdad en el mundo urbano y en el mundo rural $(\mathrm{Ca}-$ marero, 2008). En este caso, se ve también el reflejo de la jerarquía social y en algunas investigaciones se habla de los «otros rurales» (Clout, 1997; Little, 1999), que son las mujeres, los inmigrantes, pobres y homosexuales, quienes muestran una mayor predisposición a migrar (Paniagua, 2007).

Las mujeres, a la hora de decidir migrar, muestran estímulos estructurales más allá de factores económicos: el sistema patriarcal, la división del trabajo en el mercado, la subordinación en el ámbito doméstico (Soronellas, Bodoque, Roquer, y Torrens, 2013).

Según Chulvi (1999), las limitaciones que presenta el medio rural comparado con el urbano tienen que ver con su amplitud geográfica, sus niveles demográficos y las actividades que se desarrollan. Boserup (1970) fue la persona que puso por primera vez en relieve el tiempo que consumen estas tareas, y las penalidades que causan a las mujeres de las zonas rurales. Éstas se ven obligadas a hacer grandes esfuerzos físicos buscando leña, acarreando agua, ocupándose de los cultivos y de la «elaboración rudimentaria de alimentos esenciales». Además, Lourdes Benería (1999) afirma que, al estar el trabajo agrícola no remunerado muy integrado en las actividades domésticas, la distinción entre el trabajo familiar tradicional en la agricultura y el trabajo doméstico es muy sutil. Sin ir más lejos, la explotación familiar agraria según Millán (2002), es considerada la actividad socioeconómica donde mejor se refleja la confusión entre el trabajo doméstico reproductivo y el trabajo remunerado productivo. El trabajo de las mujeres en las explotaciones familiares suele ser considerada complementaria, y su labor reside en la cohesión del tejido social de su familia y su explotación (Muñiz, 2002).

Convendría analizar la situación en zonas rurales teniendo en cuenta que, en el ámbito rural, la aportación de las mujeres a la explotación agraria familiar ha sido desvalorizada y carente de reconocimiento social y económico (Sampedro, 1996; Camarero, 2006). De hecho, en el mundo rural, las mujeres han sido con frecuencia olvidadas y marginadas, se han considerado productoras dependientes, vinculadas al modelo de producción familiar basado en una rígida ideología patriarcal, observadoras en silencio y sujetos pasivos en la modernización rural y en sus discursos (Baylina y Salamańa, 2006). Camarero (2008) opina que es por una doble invisibilidad que viene de la dicotomía rural/urbana, una desvalorización de la actividad rural y del trabajo femenino. 
Camarero (2008) sostiene que el mayor hándicap para lograr la sostenibilidad social en estas zonas es la masculinización rural y agraria. Según Camarero, esto es debido a los desequilibrios demográficos de las poblaciones rurales, las formas familiares de subsistencia, pocas oportunidades en el mercado laboral y las dificultades de movilidad. Los grandes flujos de migración femenina a núcleos urbanos de las últimas décadas del siglo xx se dieron en gran parte debido a la ausencia de alternativas a las actividades tradicionales. Éstas, difícilmente permitían la emancipación de las mujeres a través del empleo (Chulvi, 1999). La tasa de natalidad en el mundo rural disminuyó y la esperanza de vida de la sociedad rural aumentó (Libro Blanco, 2003, pp. 197) lo que también ha llevado al envejecimiento de la población rural.

Además, el envejecimiento de la población ha generado una gran carga de trabajo de cuidados de personas dependientes para las mujeres rurales (Baylina, 2019). Éstas se ven afectadas por las expectativas que tienen la familia y la comunidad sobre ellas (Baylina y Salamańa, 2006). La idea de la familia tradicional, y los valores y roles asociados al hombre y a la mujer en el contexto rural suponen una barrera ideológica difícil de cambiar y sigue siendo inusual la corresponsabilidad al 50\% del trabajo de cuidados (Baylina et al., 2015). En el tema de la conciliación de trabajos del hogar, la dicotomía rural/urbano aparece a pesar de la cercanía o accesibilidad a los centros urbanos. Según las autoras, se considera que donde más cambios se han producido ha sido en las ciudades y que el mundo rural se plantea como un espacio menos abierto a cambios en las relaciones de género.

Es así, que la falta de reconocimiento a su trabajo, las pocas oportunidades de acceder a un empleo en otro tipo de actividades no agrarias en los pueblos, sumado a la progresiva decadencia social y económica de las áreas rurales, han llevado al abandono de estas zonas y principalmente por las mujeres (Camarero y Sampedro, 2008; Rico y Franco, 2009). En efecto, que en el espacio rural del estado español haya un notable mayor número de hombres que de mujeres, sobre todo en edades intermedias, es un dato bastante significativo (Baylina, Garcia, Porto, Salamaña, \& Villarino, 2015). Baylina y Salamaña (2006) afirman que es imprescindible analizar el trabajo remunerado de las mujeres en el mundo rural para entender los procesos migratorios a áreas urbanas.

\subsection{Nueva re-ruralización}

En las zonas donde todavía hay cierto nivel de población, existe evidencia empírica que muestra que explotar nuevas vías de empleo puede suponer recuperar la vida diaria en los pueblos (González, 2008). De hecho, 
parece que estamos entrando en una nueva era y que las cosas empiezan a cambiar para el mundo rural. Según varios estudios, en Europa se está observando una tendencia de retorno al medio rural por mujeres y hombres adultos jóvenes, muchos con estudios superiores, que se instalan en estas áreas para el desarrollo de proyectos profesionales propios (Baylina, Garcia, Porto, Mosteiro, M., Salamaña, \& Villarino, 2019). Estos procesos de re-ruralización muestran también nuevas masculinidades y feminidades (Baylina \& Berg, 2010; Bryant \& Pini, 2011; Pini \& Leach, 2011; Camarero, 2013; Forsberg \& Stenbacka, 2013; Little, 2015). En la literatura existen aportaciones que tratan de explicar estos procesos migratorios, aunque no abordan el estudio desde una perspectiva de género (Hedberg \& Do Carmo, 2012; Monllor \& Fuller, 2016; Viladomiu \& Rosell, 2016; Woods, 2016; Taboadela, Maril, \& Lamela, 2018).

Según Baylina et al. (2015) las mujeres emprendedoras en el ámbito rural están ampliando los significados del género sobre la empresa, y con sus experiencias y ejemplos están creando nuevas oportunidades para otras mujeres también. Como afirma (Baylina et al., 2006), las actividades de las mujeres en comunidad pueden amenazar las relaciones de poder establecidas. Existe una necesidad de análisis feminista del medio rural para poder entender las relaciones de género y de poder rurales, no solo en la dicotomía del género, sino reconociendo también la interseccionalidad de otras relaciones más complejas (Baylina et al., 2019).

\section{Metodología}

La metodología para el trabajo se basará en técnicas cuantitativas y cualitativas. Los datos cuantitativos serán secundarios y los datos cualitativos serán primarios y se lograrán mediante entrevistas personales. Por un lado, las fuentes de información de los datos cuantitativos serán el Instituto de Estadística de Navarra (Nastat) y el citado informe sobre desigualdades territoriales en Navarra. Por otro lado, las fuentes cualitativas se conseguirán mediante entrevistas personales a mujeres rurales del ámbito de la Economía Social y Solidaria. Para la identificación de las mujeres que van a ser entrevistadas, se han tenido en cuenta contactos propios, se ha contactado con sindicatos y con asociaciones del sector, como el Consejo de Producción Agraria Ecológica Navarra (CPAEN). Para obtener más contactos y se ha pedido a Geltoki ${ }^{3}$ una lista de participantes de la feria de Economía social y solidaria que se organiza todos los años en el mismo recinto. Geltoki

\footnotetext{
3 Geltoki. Más información disponible en; http://www.geltoki.red/
} 
es un proyecto establecido en la antigua estación de autobuses de Pamplona, que busca la promoción de la economía social y solidaria, autosuficiencia económica y la construcción de una iniciativa abierta y plural que fomente el tejido social. Algunos nombres y teléfonos de mujeres se consiguieron a través de contactos propios y otros consultando en internet.

Por otro lado, las entrevistas han sido semiestructuradas, con una base de preguntas preparadas con antelación, aunque fueron adaptadas al curso de la conversación en cada caso. Las entrevistas se hicieron por teléfono, fueron grabadas y transcritas textualmente a posteriori para su análisis. Una de las limitaciones presentadas, ha sido consecuencia de la pandemia sufrida por el COVID-19. La idea inicial era acudir a la feria de economía social de Geltoki, organizada por REAS. Sin embargo, las entrevistas en vez de hacerse en persona tuvieron que ser por teléfono, perdiendo parte de la información que se puede obtener en una entrevista presencial.

\section{Estudio de caso: Nafarroa}

\subsection{Despoblación navarra hoy en dia}

\subsubsection{ANÁlisis de LA SITUACiÓN DEMOgráfica}

El aumento de la población Navarra de las últimas décadas no se ha repartido de forma uniforme por todo el territorio. Según datos de Nastat (Nafarroako Estatistika Erakundea/Instituto Navarro de Estadística) en enero de 2019 la población Navarra ascendía a 654.214 personas. Sin embargo, en 2019 el 58\% de la población, es decir, 379.955 personas, residían en municipios de más de 10.000 habitantes, 12 municipios en toda Navarra. La mayoría vive en Pamplona, que tiene una población de 201.653 personas. En los 260 municipios restantes, es decir, en el $95,6 \%$ de los municipios de Navarra, reside un $42 \%$ de toda la población.

El gráfico 1 muestra el cambio en la distribución de la población de Navarra del año 1990 al año 2019. En el gráfico se ve como los municipios de más de 3.000 habitantes han aumentado su población con respecto a 1990. En especial, el mayor cambio se ha dado en los municipios de entre 10.000 y 25.000 habitantes, que han doblado su población en 30 años. Los municipios con menos de 2.000 habitantes han reducido su población, y los de entre 2.000 y 3.000 lo han mantenido. Es por esto que, en los siguientes análisis realizados según el tamaño del municipio, la muestra estará en aquellos municipios de menos de 3.000 habitantes. 


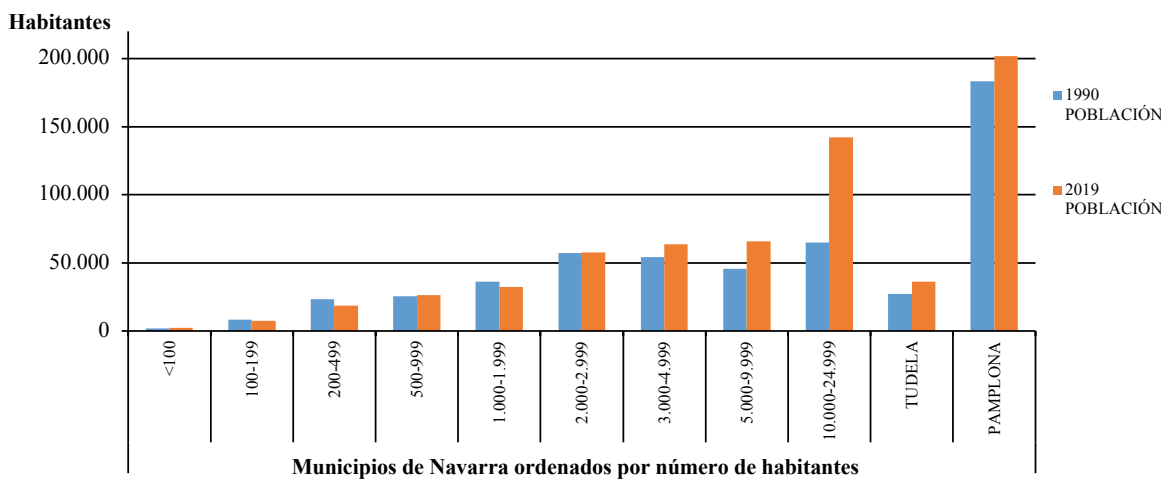

Fuente. Elaboración propia a partir de datos de Nastat.

\section{Gráfico 1}

Distribución de la población de Navarra según tamaño del municipio

En 1990 los municipios de menos de 2.999 habitantes albergaban casi el $29 \%$ de la población navarra. En 2019, ese porcentaje ha bajado al 22\%. Teniendo en cuenta la proporción a la que ha disminuido la población que vive en los pueblos más pequeños de Navarra, se estima que, dentro de 30 años, en el año 2050, si la tendencia a la baja se mantiene, el porcentaje será de un 15\%. Además, en el 2019 se censaron 43 pueblos con menos de 100 habitantes. Estos son considerados escenarios en riesgo de despoblación. La mayoría de estos pueblos, se dedican principalmente a actividades del primer sector. Algunos de estos pueblos en las dos últimas décadas han visto su población reducida casi a la mitad. Mirando los datos desde una perspectiva de género, en un primer acercamiento y con datos descargados del Instituto Navarro de Estadística, se observa cómo la despoblación tiene un sesgo de género. Escogiendo los pueblos de fuera de la comarca de Pamplona y de menos de 3.000 habitantes, en el año 2019, de 234 pueblos que quedan en la muestra, sólo 31 (esto es el 13\%), tuvieron más habitantes mujeres que hombres.

Es importante aclarar que la ruralidad es dispar en los municipios cercanos a un área metropolitana y en los pueblos remotos de montańa. Es por esto, que es fundamental analizar la situación demográfica en Navarra por zonas.

Tal y como recoge el informe del Gobierno de Navarra publicado en enero del 2020 por el observatorio de realidad social sobre desigualdades territoriales $^{4}$, la montaña pirenaica, la cuenca de Pamplona, el eje del Ebro,

${ }^{4}$ Observatorio de la Realidad Social Navarra (2020) Desigualdades Territoriales en Navarra. Disponible en: https://bit.ly/2UpyeQG 
la Navarra Atlántica y la Navarra media son territorios muy diversos. En el Mapa 1, se observan las diferentes zonas de Navarra que se nombran en los análisis siguientes.

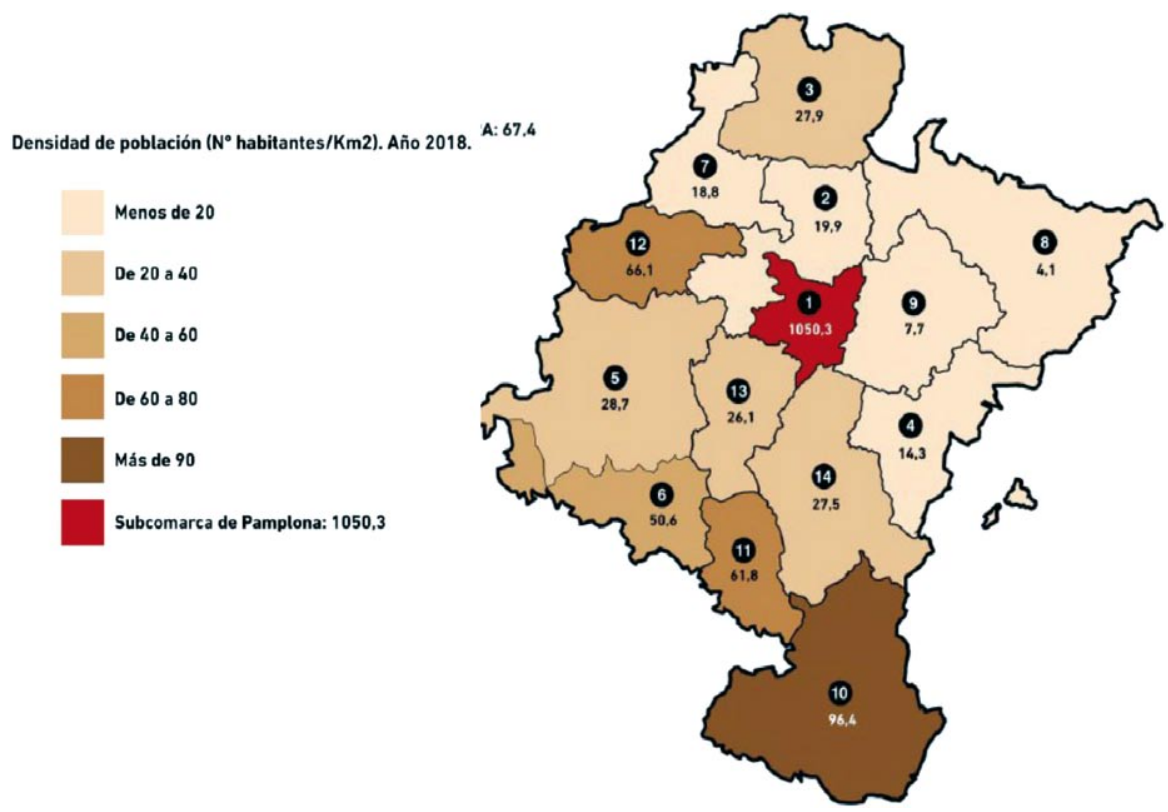

Fuente. Informe sobre desigualdades territoriales, Observatorio realidad social de Navarra (2020).

\section{Mapa 1}

Densidad poblacional por comarcas 5

Además, como muestra el siguiente mapa que refleja el número de habitantes por kilómetro cuadrado, la comarca de Pamplona es la zona más poblada con 1.050,3 personas por kilómetro cuadrado. Se puede observar que la zona más afectada por la despoblación es la del Pirineo (8), que en el 2018 registró 4,1 habitantes por kilómetro cuadrado. Las zonas con

5 1. Arga: Subcomarca de Pamplona/Iruñerria 2. Arga: Valles/ibarrak 3. Bidasoa 4. Comarca de Sangüesa/ Zangozeira 5. Ega: Montejurra / Jurramendi 6. Ega: Ribera Estellesa/Lizarraldeko Erribera 7. Larraun-Leitzaldea 8. Pirineo / Pirinioak 9. Prepirineo / Pirinioaurrea 10. Ribera 11. Ribera Alta / Erribera Garaia 12. Sakana 13. Valdizarbe -Novenera / Izarbeibar - Norbenera 14. Zona media / Erdialdea. 
menos de 20 habitantes por kilómetro cuadrado son también los valles del Arga (2), la comarca de Sangüesa (4), Larraun (7) y el Prepirineo (9).

Según el informe del Gobierno de Navarra, en la mayoría de municipios rurales la masculinización se da en las edades jóvenes e intermedias, debido, señalan, principalmente a la significativa emigración femenina en esas edades, dada por la falta de igualdad en el trabajo productivo y reproductivo. Además, el aumento del envejecimiento en las zonas rurales de Navarra, ha supuesto un aumento en el trabajo de cuidados que se atribuye a las mujeres.

Como se puede observar en la tabla 1, el Instituto Navarro de Estadística ofrece los datos de la distribución de la población en el 2019 por tres rangos de edad: de 0 a 15, de 16 a 64 (personas en edad de trabajar) y mayores de 65. Los datos totales muestran la proporción de mujeres y de hombres en cada zona. En relación con el análisis previo sobre la proporción de hombres y mujeres en pueblos pequeños, no es de extrañar que sea el pirineo, la zona con pueblos pequeños y en la montańa, la zona con una proporción más desigual. De hecho, en esta zona el porcentaje es de un $54 \%$ hombres y un $46 \%$ mujeres.

\section{Tabla 1}

Distribución población por zonas de Navarra

\begin{tabular}{|c|c|c|c|c|c|c|c|c|c|c|c|c|}
\hline & \multicolumn{4}{|c|}{$\%$ mujeres y hombres / total zona } & \multicolumn{4}{|c|}{$\%$ hombres / total zona } & \multicolumn{4}{|c|}{$\%$ mujeres / total zona } \\
\hline 2.019 & Total & $\begin{array}{r}\text { De } 0 \text { a } \\
15 \text { años }\end{array}$ & $\begin{array}{l}\text { De } 16 \text { a } \\
64 \text { años }\end{array}$ & $\begin{array}{c}\text { De } 65 \text { y } \\
\text { más } \\
\text { años }\end{array}$ & Total & $\begin{array}{c}\text { De 0 a } \\
15 \\
\text { años }\end{array}$ & $\begin{array}{l}\text { De } 16 \\
\text { a } 64 \\
\text { años }\end{array}$ & $\begin{array}{c}\text { De } 65 \\
\text { y más } \\
\text { años }\end{array}$ & Total & $\begin{array}{l}\text { De } 0 \\
\text { a } 15 \\
\text { años }\end{array}$ & $\begin{array}{l}\text { De } 16 \\
\text { a } 64 \\
\text { años }\end{array}$ & $\begin{array}{l}\text { De } 65 \\
\text { y más } \\
\text { años }\end{array}$ \\
\hline 1 Noroeste & 56.168 & 17 & 62 & 21 & 52 & 9 & 33 & 10 & 48 & 8 & 29 & 11 \\
\hline 2 Pirineo & 14.863 & 14 & 62 & 24 & 54 & 7 & 34 & 12 & 46 & 7 & 27 & 12 \\
\hline 3 Pamplona & 368.464 & 17 & 65 & 18 & 48 & 9 & 32 & 8 & 52 & 8 & 33 & 10 \\
\hline 4 Tierra Estella & 37.146 & 14 & 61 & 25 & 51 & 7 & 32 & 11 & 49 & 7 & 29 & 13 \\
\hline 5 Navarra Media Oriental & 31.429 & 14 & 62 & 24 & 51 & 7 & 33 & 11 & 49 & 7 & 29 & 13 \\
\hline 6 Ribera & 57.258 & 16 & 63 & 21 & 51 & 8 & 33 & 10 & 49 & 8 & 30 & 12 \\
\hline 7 Tudela & 88.886 & 17 & 64 & 19 & 50 & 9 & 33 & 9 & 50 & 8 & 31 & 11 \\
\hline
\end{tabular}

Fuente. Elaboración propia a partir de los datos de Nastat.

Respecto a las edades intermedias, los porcentajes más altos están en Pamplona y Tudela, que a su vez son las zonas donde menos envejecimiento se observa. En este sentido, Tierra Estella es la que menos población tiene en edad de trabajar, que tiene un $61 \%$ de su población. Además, es la zona que más población envejecida tiene en términos relativos. Su población de más de 65 años alcanza el 25\% de sus habitantes.

En cuanto a la masculinización de la población, la zona más afectada son los Pirineos, que, de su población en edades intermedias, un 34\% son hombres y un $27 \%$ son mujeres, mientras que en Pamplona la proporción 
es 32\% hombres y 33\% mujeres. Por otro lado, para las edades de más de 65 años la proporción de mujeres es mayor que las de los hombres en la mayoría de las zonas (la esperanza de vida de las mujeres es superior a la de los hombres). Tanto en Tierra Estella como en la Navarra Media Oriental el 13\% de la población son mujeres de más de 65 años mientras que los hombres de el mismo rango de edad son el $11 \%$. Esto difiere de los datos de Pamplona donde las proporciones son $10 \%$ mujeres de más de 65 y el $8 \%$ hombres de las mismas edades.

\subsubsection{Distribución De LOS USOS DEL TIEMPo ENTRE hombres Y MUJERES}

Es interesante hablar del uso del tiempo en los hogares de Navarra. Este dato nos puede dar información que no se recoge en otras fuentes estadísticas socioeconómicas como pueden ser las tasas de participación laboral o la de paro. Esta encuesta refleja una imagen de la realidad de los hogares navarros y de la distribución de las tareas de sostenibilidad de la vida. La última encuesta del empleo del tiempo disponible en Navarra es del año 2010 y fue elaborada por el Instituto Navarro de Estadística. No se disponen de estos datos por zonas o municipios.

Los datos de la última encuesta realizada muestran la desigual distribución del uso del tiempo de hombres y mujeres en Navarra. Es destacable que, en el trabajo remunerado, principal y secundario, los hombres de media pasan 2 horas y 10 minutos más que las mujeres cada día. Esto se puede deber a una mayor participación de los hombres en el mercado laboral o por la frecuencia en la que las mujeres son contratadas en empleos temporales y a tiempo parcial.

Además, queda de manifiesto la desigual responsabilidad de las tareas del hogar asumida por mujeres y por hombres en el conjunto de la población navarra. Las mujeres dedican 4 horas y 10 minutos al hogar y al cuidado de la familia, mientras que los hombres dedican 2 horas y 36 minutos de media al día. Las diferencias se ven especialmente en actividades culinarias, confección y cuidado de ropa y el cuidado de niños y niñas. Por otro lado, los hombres navarros pasan de media casi 4 horas al día en jardinería y cuidado de animales, mientras que las mujeres en esto pasan poco más de 1 hora.

Es también relevante el hecho de que las mujeres dedican más tiempo en su día a día al trabajo voluntario en organizaciones, en ayudas informales a otros hogares y en actividades participativas, como reuniones, por ejemplo. Por último, señalar que los hombres emplean más tiempo haciendo ejercicio físico y actividades relacionadas con los deportes, hasta 1 hora y 30 minutos más cada día. 
Tabla 2

Encuesta del empleo del tiempo Navarra año 2010 (última disponible)

\begin{tabular}{|c|c|c|}
\hline & \multicolumn{2}{|c|}{$\begin{array}{l}\text { Duración media } \\
\text { diaria en horas }\end{array}$} \\
\hline & Hombres & Mujeres \\
\hline 0 CUIDADOS PERSONALES & $11: 31$ & $11: 32$ \\
\hline 1 TRABAJO REMUNERADO & $7: 53$ & 6:22 \\
\hline 11 Trabajo principal y secundario & $9: 43$ & 6:34 \\
\hline 111 Trabajo principal y secundario & $9: 43$ & $6: 34$ \\
\hline 12 Actividades relacionadas con el trabajo & $1: 26$ & $1: 26$ \\
\hline 121 Pausa para la comida & $0: 00$ & $0: 00$ \\
\hline 122 Búsqueda de empleo & $2: 23$ & $2: 36$ \\
\hline 129 Otras act. relacionadas con el trabajo, especific. o no & $0: 18$ & $0: 14$ \\
\hline 2 ESTUDIOS & $5: 36$ & $5: 11$ \\
\hline 3 HOGAR Y FAMILIA & 2:36 & 4:10 \\
\hline 31 Actividades culinarias & $0: 40$ & $1: 38$ \\
\hline 32 Mantenim iento del hogar & $0: 25$ & 1:05 \\
\hline 33 Confección y cuidado de ropa & 0:04 & 1:04 \\
\hline 34 Jardinería y cuidado de animales & $3: 44$ & $1: 10$ \\
\hline 35 Construcción y reparaciones & $1: 28$ & 1:04 \\
\hline 36 Compras y servicios & $0: 32$ & 1:05 \\
\hline 37 Gestiones del hogar & $0: 28$ & $0: 40$ \\
\hline 38 Cuidado de niños & $1: 21$ & 2:23 \\
\hline 39 Ayudas a adultos miem bros del hogar & $0: 58$ & $1: 22$ \\
\hline 4 TRABAJO VOLUNTARIO Y REUNIONES & $1: 22$ & $1: 27$ \\
\hline 41 Trabajo voluntario al servicio de una organización & 2:08 & 2:57 \\
\hline 42 Ayudas informales a otros hogares & $0: 50$ & $1: 28$ \\
\hline 43 Actividades participativas & $0: 41$ & 1:00 \\
\hline 5 VIDA SOCIAL Y DIVERSIÓN & $1: 50$ & $1: 49$ \\
\hline 6 DEPORTES Y ACTIVIDADES AL AIRE LIBRE & 2:04 & $1: 35$ \\
\hline 61 Ejercicio físico & 2:16 & $1: 35$ \\
\hline 62 Ejercicio productivo (caza, pesca...) & $2: 33$ & $3: 59$ \\
\hline 63 Actividades relacionadas con los deportes & $1: 10$ & $0: 15$ \\
\hline
\end{tabular}

Fuente. Elaboración propia a partir de los datos de Nastat.

\subsubsection{Mercado laboral}

La desigual distribución en el empleo del tiempo entre hombres y mujeres nos lleva a preguntarnos por las consecuencias que esto puede tener a la hora de acceder al mercado laboral. La falta de tiempo, o la distribución 
desigual de las tareas puede incidir en el grado en el que las mujeres deciden o pueden participar en el empleo remunerado.

Por otro lado, es también interesante, ver de toda la población en edad de trabajar cuánta es la proporción que está empleada. Por la dedicación de las mujeres a las tareas no remuneradas, podría esperarse una gran diferencia entre hombres y mujeres. De hecho, analizando la tasa de actividad y la tasa de empleo, en los siguientes gráficos se puede observar, por un lado, las grandes diferencias entre mujeres y hombres y por otro lado las diferencias entre mujeres urbanas y rurales.

En la tasa de actividad, los hombres, en la última década se ha mantenido en un rango entre el $70 \%$ y el $62 \%$ en los últimos años. Las mujeres, en cambio, se han mantenido entre el $45 \%$ y el $50 \%$. La tasa de empleo también cambia considerablemente de hombres a mujeres. Los hombres comenzaron 2005 con una tasa de empleo cercana al 65\% en todas las zonas. Las diferencias entre las comarcas se vieron reducidas durante la crisis, sufriendo una caída importante hasta casi llegar a una tasa del 50\% en algunos territorios. En los últimos ańos la tasa se ha vuelto volátil y han aumentado las diferencias demográficas. En el caso de las mujeres, aunque parece que ha habido una leve subida, casi todas las zonas se han mantenido entre una tasa de empleo entre el 40 y el $45 \%$.

El aspecto más destacable de estos datos y gráficos, es la diferencia entre mujeres rurales y mujeres urbanas. Los gráficos muestran claramente una mayor tasa de actividad y de empleo en la zona de Pamplona con respecto al resto de zonas de Navarra. Para el conjunto del periodo estudiado la diferencia asciende a unos 5 puntos porcentuales.

Estos datos muestran las consecuencias no de vivir en el mundo rural, sino de vivir en el mundo rural siendo mujer.
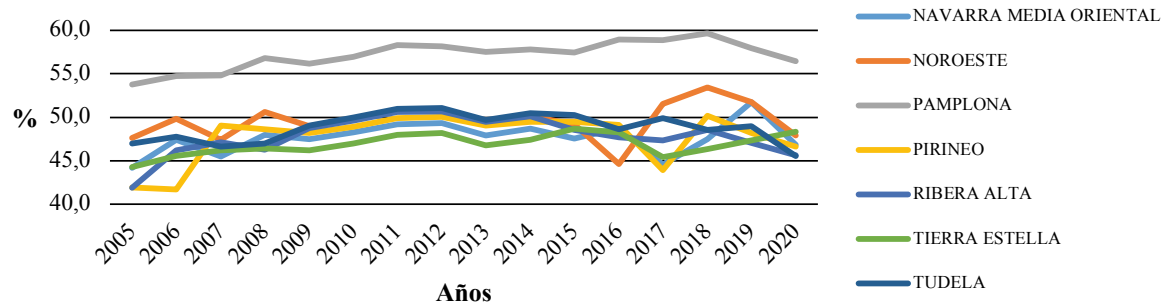

Gráfico 2

Tasa de actividad mujeres Navarra 
DESPOBLACIÓN EN NAVARRA, NUEVAS OPORTUNIDADES DESDE LA ECONOMÍA SOCIAL Y...

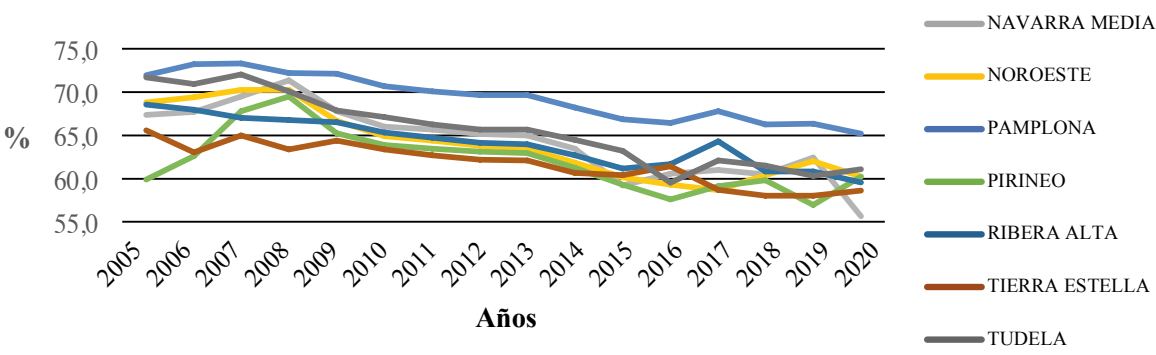

Gráfico 3

Tasa de actividad hombres Navarra

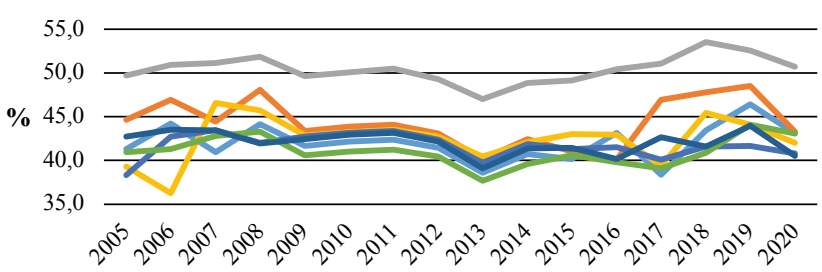

Años

\section{Gráfico 4}

Tasa de empleo mujeres Navarra

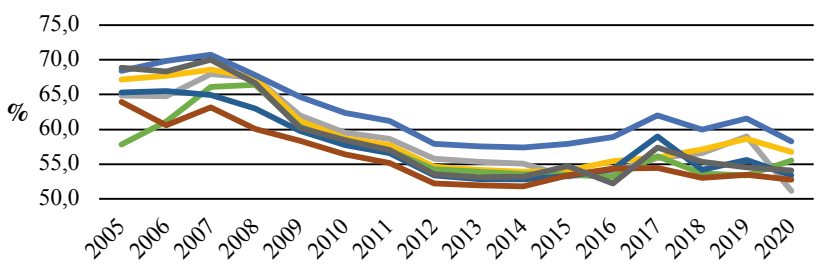

Años

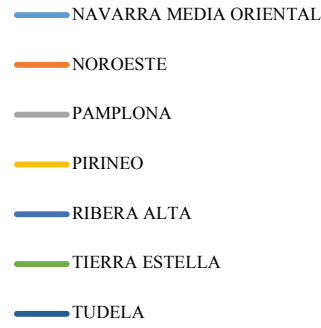

NAVARRA MEDIA ORIENTAL

NOROESTE

$\longrightarrow$ PAMPLONA

$\longrightarrow$ PIRINEO

$\longrightarrow$ RIBERA ALTA

TIERRA ESTELLA

TUDELA

Fuente. Elaboración propia a partir de los datos de Nastat.

\section{Gráfico 5}

Tasa de empleo hombres Navarra 
Otra de las problemáticas en el mundo rural, es la menor afiliación a la seguridad social por parte de mujeres que de hombres, que viene, de la línea invisible, muy estrecha, entre el trabajo remunerado y el no remunerado que ejercen las mujeres. La afiliación a la seguridad social es dinero que, en algunos casos, en algunos sectores, comparando con los beneficios obtenidos por ventas, sale caro. Es una casuística comentada previamente, que, en empresas familiares de agricultura o ganadería, en ocasiones sólo se inscribe a una persona a la seguridad social, figurando esa persona como única trabajadora de la empresa. Frecuentemente, los hombres son los que se afilian a la seguridad social aunque las mujeres siguen trabajando igual.

Según los datos obtenidos en Nastat para el año 2020, de las mujeres que viven en los pueblos de Navarra de menos de 3.000 habitantes y de fuera de la comarca de Pamplona y que están en edad de trabajar, un 56\% están afiliadas a la seguridad social. En cambio, en el caso de los hombres, un $63 \%$ está afiliado. Los datos hablan de personas con edad de 16 a 64 y empadronadas en municipios navarros de menos de 3.000 habitantes y de fuera de la comarca de Pamplona.

Tabla 3

Tasa de paro de Navarra según zonas y género, ańo 2018

\begin{tabular}{lrrr}
\hline & Total & Hombres & Mujeres \\
\hline Arga: Subcomarca de Pamplona / Iruñerria & 9,89 & 9,47 & 10,32 \\
Arga: Valles / Ibarrak & 6,92 & 6,44 & 7,51 \\
Bidasoa & 5,95 & 4,50 & 7,67 \\
Comarca de Sangüesa / Zangozeira & 7,52 & 6,96 & 8,26 \\
Ega: Montejurra / Jurramendi & 9,92 & 8,68 & 11,51 \\
Ega: Ribera Estellesa / Lizarraldeko Erribera & 13,42 & 12,17 & 14,97 \\
Larraun-Leitzaldea & 6,05 & 4,01 & 8,64 \\
Pirineo / Pirinioak & 6,48 & 6,99 & 5,76 \\
Prepirineo / Pirineoaurrea & 12,95 & 13,21 & 12,59 \\
Ribera & 11,91 & 9,97 & 14,35 \\
Ribera Alta / Erribera Garaia & 10,45 & 8,59 & 12,80 \\
Sakana & 10,99 & 7,48 & 15,30 \\
Valdizarbe-Noverena / Izarbeibar-Noberena & 8,14 & 7,06 & 9,59 \\
Zona Media / Erdialdea & 9,17 & 8,09 & 10,55 \\
\hline Navarra & 10,03 & 9,09 & 11,09 \\
\hline
\end{tabular}

Fuente. Informe sobre desigualdades territoriales. 
Los niveles de participación y de ocupación de las mujeres navarras son entonces bastante más bajos que las de los hombres. Además, se puede analizar, si una vez que las personas «deciden» entrar al mercado de trabajo remunerado, es decir, convertirse en población activa, hombres y mujeres tienen las mismas oportunidades de encontrar empleo. Para ello, podríamos analizar la tasa de paro, que nos dirá, cuántas personas que están buscando trabajo remunerado, no lo han conseguido todavía.

En relación al empleo, en la tabla 3, el informe de desigualdades territoriales del observatorio de realidad social muestra la tasa de paro del año 2018 según zonas y según género en Navarra. La tasa de paro fue mayor para las mujeres que para los hombres en todas las zonas analizadas, a excepción del Pirineo y Prepirineo Navarro. Es decir, en general, en casi todas las zonas de Navarra, la proporción de mujeres que buscaban empleo remunerado y no lo conseguían era mayor que la de los hombres.

Analizando el caso de los Pirineos, en el siguiente gráfico podemos observar como en el paro de las mujeres en la zona en los últimos años, se observa una tendencia anual similar. De hecho, la tasa de paro disminuye en el último trimestre de cada ańo, y en el primer trimestre vuelve a subir. La zona del pirineo está impulsando su sector turístico y se está convirtiendo en una entrada de dinero y oportunidad de empleo notable para la zona. Debido a la tendencia a ocupar actividades del sector de servicios, la estacionalidad del paro de las mujeres en los pirineos, podría estar relacionada con el impulso del turismo de invierno en la zona. Como muestran los gráficos, esto no ocurre con la tasa de paro de los hombres de la zona.

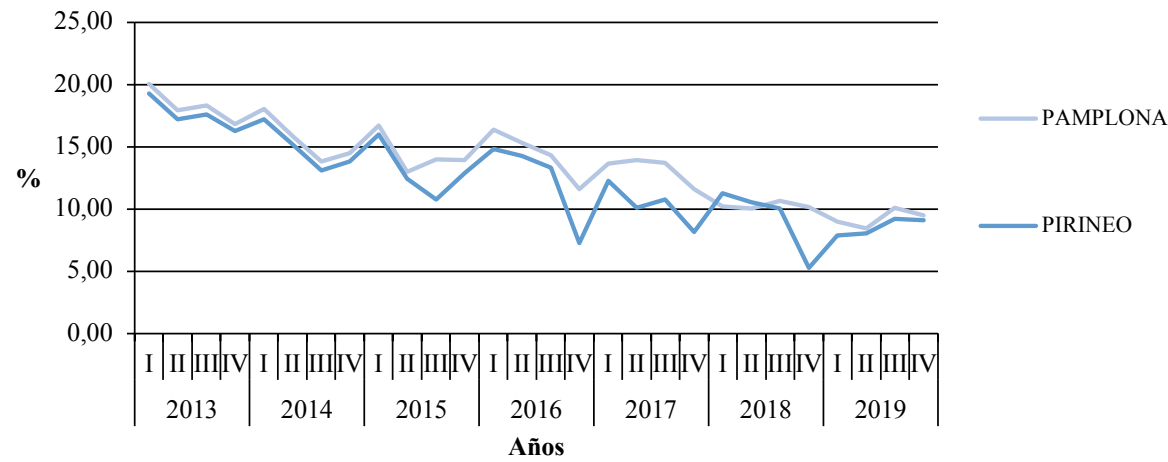

Fuente. Elaboración propia a partir de datos de Nastat.

\section{Gráfico 6}

Tasa de paro mujeres Pamplona y Pirineos últimos años 


\subsection{Politicas públicas en contra de la despoblación, 2019-2020}

Una vez analizada la situación actual en Navarra en torno a la despoblación, es interesante ver qué se está haciendo ahora, hoy en día, desde instituciones y administraciones para frenarlo. En febrero del 2019, tras varios años invertidos en su elaboración, se aprobó en el parlamento de $\mathrm{Na}$ varra la LEY FORAL 4/2019, DE 4 DE FEBRERO, DE REFORMA DE LA ADMINISTRACIÓN LOCAL DE NAVARRA ${ }^{6}$. Esta ley nace con el objetivo de establecer la 'implantación de un nuevo modelo de financiación acorde con los principios de suficiencia financiera, sostenibilidad presupuestaria, solidaridad y autonomía local y equilibrio territorial'. La Ley Foral 4/2019, busca 'conseguir una financiación que garantice la suficiencia económica para hacer frente a las competencias y obligaciones locales, que haga visible el principio de equilibrio y cohesión territorial de Navarra y que dé valor a la solidaridad entre municipios'.

Esta reforma afecta a fondos de haciendas locales de transferencias corrientes y de capital, y también a los tributos municipales. Para esto, el territorio se distribuye por comarcas y subcomarcas y se plantea poner en común financiación y recursos, "superando visiones excesivamente unilaterales", para que la mejora de los servicios a la ciudadanía se garantice en todo el territorio. Desde el departamento de Administración Local se realizó un análisis del coste de proporcionar en cada comarca una serie de servicios públicos mínimos entre los que estaban las escuelas infantiles, consultorios médicos, colegios, escuelas de música, bibliotecas...

En definitiva, el objetivo es dar una mayor cobertura de servicios al conjunto de la ciudadanía, reforzar el autogobierno local y reducir los desequilibrios entre los diferentes ámbitos territoriales de Navarra, en palabras de la Consejera de Desarrollo Rural de Navarra ${ }^{7}$. Esta Ley se considera la culminación de un proceso participativo de dos ańos. El texto recibió la aprobación mayoritaria de las entidades locales que se reunieron en la asamblea de la Federación Navarra de Municipios y concejos.

Con el cambio de legislatura, en agosto de 2019, el Gobierno de Navarra también creó, bajo el departamento de Cohesión Territorial ${ }^{8}$, la dirección general de Administración Local y Despoblación11 (hasta entonces llamada dirección general de Administración Local y ubicada bajo el de-

${ }^{6}$ Ley Foral 4/2019, de 4 de Febrero, de reforma de la administración local de Navarra. Disponible en; http://www.lexnavarra.navarra.es/detalle.asp? $r=51129$

7 Disponible en: https://www.navarra.es/home_es/Actualidad/Sala+de+prensa/ Noticias/2018/07/04/proyecto+ley+mapa+local.htm

8 Departamento de Cohesión Territorial. Disponible en: https://www.navarra.es/es/gobierno-de-navarra/departamento-de-cohesion-territorial 
partamento de Desarrollo rural) para trabajar en contra de la despoblación en Navarra.

En Noviembre del mismo año, desde el Gobierno de Navarra se crea la "Comisión de Lucha contra la Despoblación"». El objetivo es adoptar medidas que eviten y que reviertan la situación de despoblación en Navarra, además de empezar a tener siempre en cuenta este aspecto a la hora de poner en marcha cualquier política pública. La comisión estará compuesta por la Presidenta de Navarra y el consejero del departamento de Cohesión Territorial, Bernardo Ciriza, como vicepresidente, junto con varias direcciones generales del gobierno y la Federación Navarra de Municipios y Consejos.

A su vez, en enero de 2020 el Observatorio de realidad social publicó un informe sobre Desigualdades Territoriales en Navarra haciendo un diagnóstico sociodemográfico sobre la actual distribución territorial.

Además, el Gobierno Foral anuncia en junio de 2020 su intención de poner en marcha una iniciativa que permitirá llevar la banda ancha a todas las zonas de Navarra. El objetivo es que la alta conectividad llegue a todas las casas de Navarra y se llevará a cabo entre 2020 y 2024. Según el director general de Telecomunicaciones y Digitalización del Gobierno de Navarra, Guzman Garamendia, este es un ejemplo de conectividad para luchar en contra de la despoblación en la comunidad Foral. ${ }^{10}$

\subsection{Autopercepción de la realidad por parte de las mujeres rurales navarras}

La población objeto de esta investigación han sido mujeres navarras que viven en zonas rurales, en concreto en pueblos con menos de 3.000 habitantes y se dedican a la economía solidaria. Las mujeres de la muestra seleccionada tienen entre 30 y 60 ańos. Se han realizado diez entrevistas a diez mujeres en la lengua materna de las entrevistadas (castellano o euskera). La mayoría de ellas se dedican a la agricultura y a la ganadería en su trabajo remunerado, una a la artesanía, otra a la producción de ropa sostenible, una tiene una posada y se dedica al turismo sostenible y en su restaurante solo ofrece productos de $\mathrm{km} 0$, otra tiene una herboristería de productos ecológicos y por último, también se ha entrevistado a la alcaldesa de Uztarrotz (pirineo) y primera mujer en ser presidenta de la Junta del Valle del Roncal, que aunque de profesión es profesora, dedica tiempo

9 Noticia disponible en: https://www.navarra.es/es/noticias/2019/11/13/el-gobierno-denavarra-acuerda-crear-la-comision-de-lucha-contra-la-despoblacion

${ }_{10}$ Noticia disponible en: https://bit.ly/30ql6i5 
a su huerta, a colaborar en una borda y a trabajos para frenar la despoblación desde el ayuntamiento.

Por otro lado, para obtener una mejor perspectiva de la situación actual habría sido de ayuda tener acceso a más contactos, nuevamente la situación de emergencia actual y el poco tiempo ha sido una barrera para conseguirlo. Sería importante conocer el punto de vista de las mujeres del sur de Navarra.

La siguiente tabla muestra la información básica de las mujeres entrevistadas. La población de cada uno de estos municipios es la publicada para el año 2018, en el Boletín Oficial de Navarra ${ }^{11}$.

\section{Tabla 4}

Mujeres entrevistadas para el estudio

\begin{tabular}{llrrl}
\hline Nombre & Municipio & Población & $\begin{array}{c}\text { Edad } \\
\text { entrevistada }\end{array}$ & \multicolumn{1}{c}{ Profesión } \\
\hline MO & Iturgoien & 88 & 49 & Productora queso ecológico de oveja latxa \\
JA & Uztarrotze & 160 & 29 & Maestra, alcaldesa \\
ML & Arbeiza & 168 & 45 & Apicultora \\
MU & Donamaria & 431 & 54 & Agricultora, kiwi ecológico \\
AP & Meano & 110 & 61 & Artesana, sedas \\
BU & Elbete & 271 & 55 & Turismo sostenible y restaurante ecológico \\
MC & Irurozki & 43 & 60 & Agricultora ecológica y ganadera \\
AJ & Extarri-Aranatz & 2.503 & 44 & Moda sostenible \\
AN & Egozkue & 30 & 37 & Productora de queso \\
MA & Lesaka & 2.737 & 36 & Tienda productos ecológicos \\
\hline
\end{tabular}

Fuente. Elaboración propia a partir de datos del BON e información facilitada por las entrevistadas.

La primera parte de las entrevistas se centraba en el origen de las mujeres entrevistadas. Un dato a destacar es que muchas de estas mujeres son de origen urbano y fue una decisión personal querer ir a vivir a un pueblo. Es el caso de 6 de las 11 entrevistadas. Cuatro de ellas estuvieron mucho tiempo viviendo en Iruña y 2 son de otras ciudades de fuera de Navarra. Los motivos para decidir ir al pueblo a vivir, varían entre ellas, algunas se fueron por trabajo, otras por convicción de que el pueblo iba a ser una vida mejor, otras porque sus parejas eran de allí y otras por seguir con la tradi-

11 Disponible en: https://bon.navarra.es/es/anuncio/-/texto/2019/42/52/ 
ción familiar. De las 4 restantes que tienen origen rural, 3 de ellas tuvieron que irse a vivir a una ciudad por un tiempo para poder completar sus estudios y luego volvieron a vivir al pueblo.

En cuanto a las ventajas o inconvenientes de vivir fuera del núcleo urbano, destacan varios aspectos negativos, en concreto la falta de posibilidades que deriva en un frecuente uso del coche con gasto que ello implica y el riesgo en la carretera. Relacionado con esto, varias mencionan la falta de servicios, problema que empeora con la vejez. Por el contrario, la mayoría de ellas mencionan también que vivir en el pueblo significa tener una vida más tranquila, vivir lento, cercanía con la naturaleza y tener sentido de comunidad. Alguna menciona que la mayor diferencia con una ciudad es que vivir en un pueblo da, de alguna manera, sentido de comunidad. Sienten que en la ciudad eso se pierde, ya que mucha gente es desconocida y solo se es una más.

Por otro lado, con la elección de vivir en el pueblo, las mujeres entrevistadas relacionan la elección de su modo de vida, y a su vez de pertenecer a la economía solidaria. Podemos hablar de la convicción entre muchas de estas mujeres, de que la economía solidaria es un tema de principios. A decir verdad, varias de estas mujeres afirman que es un tema de identidad propio, ellas tenían claro que, de emprender, lo querían hacer dedicándose a la economía solidaria. Aunque es relevante señalar, que algunas de ellas no lo llaman 'economía solidaria', ni saben que pertenecen a este modelo alternativo, sino que en cada caso lo llaman de una manera diferente, como puede ser producción ecológica, o moda sostenible, o artesanía, o preferencia por consumo de $\mathrm{km} 0 .$. MO señala que «cuando decidí que quería vivir de la agricultura y de la ganadería, decidí hacerlo de forma ecológica, desde el principio lo tenía claro». BU menciona que no es que apostara por la producción ecológica, sino que era algo que visto hacer en el baserri desde que era una niña. "Es asi como he vivido siempre y como he interiorizado que tenemos que vivin. AJ, preocupada por el sistema y con ganas de crear iniciativas alternativas, se planteó crear un mercado social en el valle de la Sakana. Así es como empezó su negocio de ropa, un poco sin querer, pero convencida de que quería tener un proyecto propio que fuera fiel a sus principios. La economía ecológica en este sentido también gana protagonismo.

Para MC ha supuesto ser consciente de la diversidad de semillas que existen, de la importancia de producir sin contaminar, de estar en contacto con las cosas que en la ciudad no se ven. Aunque la mayoría parece estar contenta con su dedicación a este tipo de economía, son muy conscientes y conviven con dificultades específicas que se presentan en este ámbito. MO afirma que "hay mucha ignorancia sobre el tema, muy poca gente sabe realmente qué es la producción ecológica. Pero si hay un porcentaje pequeño de la población que prefiere consumir ecológico»' Para AP, artesana de seda eco- 
lógica, el problema es vender ya que afirma que no existen canales de distribución necesarios para dar visibilidad. A esta situación, además, se le ha sumado la situación de pandemia, haciendo que muchas ferias donde antes vendía se hayan visto anuladas. AJ coincide con ella y ve una gran necesidad en reabrir las ferias artesanas. En el caso de MA, el problema es la percepción de la gente con el precio. Ella defiende que mucha gente ni siquiera entra a la tienda pensando que todo va a ser muy caro, cuando no tiene por qué. Además, cree que hay que visibilizar el problema de la distribución del precio de los productos que se compran en las tiendas convencionales y enseñar qué poco le llega a los y las productoras.

Sin embargo, creen que la gente de pueblo tiene una percepción diferente a la gente de ciudad en este tema. Algunas ven relación en vivir en el pueblo y tener sentimiento solidario y comunitario. Un aspecto destacable que ha salido en alguna de las conversaciones es la socialización. Algunas de las entrevistadas mencionan que las relaciones entre la gente son diferentes en la ciudad y en el pueblo. ML está convencida de que la gente en el pueblo es mucho más solidaria que en la ciudad. Sostiene que en los pueblos siempre se ha realizado trabajo comunitario, antes se repartían el trabajo y se ayudaban los/as unos/as a los/as otros/as. Aunque cree que de eso queda poco, lo que se mantiene defiende que se concentra en los pueblos. JA por ejemplo dice que la socialización se da mucho también mientras se trabaja. Esto es un reflejo de lo que también se ha comentado previamente, la fina línea en el mundo rural del trabajo doméstico remunerado y el no remunerado que realizan las mujeres. Por cierto, JA sigue diciendo que «los trabajos domésticos los repartimos. Y en la borda somos 3. Bueno en sí son dos, los dos hombres y yo suelo estar ayudando», siendo ella la que «ayuda».

Los trabajos de cuidados siguen recayendo en responsabilidad de las mujeres. BU cree que es un papel que las mujeres han asumido siempre y que se mantiene en el tiempo. En el caso de AN, comenta que es muy difícil cambiar los hábitos que ya están establecidos. Por otro lado, varias de las entrevistadas dicen que en casa reparten bastante las tareas, aunque, si uno de los dos tiene que hacer más trabajo doméstico, es siempre ella la que lo hace. Varias de las entrevistadas por otro lado, afirman que en casa ellas siguen haciendo más pero que también hay tareas de fuera del hogar, que ellas tampoco quieren hacer y hacen sus maridos, como conducir el tractor, por ejemplo.

Uno de los aspectos que parece ser determinante es vivir y trabajar en el pueblo. Por un lado, creen que ayuda mucho tener un trabajo en el pueblo a la hora de decidir establecerse, pero también es importante el impacto que esto tiene en el entorno. Defienden que estar activa en el pueblo también favorece al bienestar de las personas y de los comercios que tienen alrededor y que al final se forma una cadena. Para algunas de estas mujeres, 
poder vivir y trabajar en el pueblo, ha supuesto un desahogo y estabilidad a la hora de poder seguir con el trabajo de cuidados.

En la percepción de la despoblación se nota mucha diferencia en las respuestas de las mujeres que viven en los pueblos más "grandes» o que tienen otro pueblo muy grande o una ciudad cerca. De hecho, le dan mucha importancia a la localización. Las mujeres que viven en la zona de Sakana y cerca de pueblos grandes como Bera, por ejemplo, destacan la buena localización y que esto haya permitido que la gente se quede en los pueblos. $\mathrm{BU}$, cree que en la zona de Baztan está habiendo un cambio. Durante unos años la gente de los pueblos pequeños del valle se fue a vivir a Elizondo, «la capital del valle» pero últimamente está pasando lo contrario.

Sin embargo, en pueblos como Meano, Uztarrotz, Irurozki las respuestas son muy diferentes. MC no reconoce el pueblo de su infancia, Irurozki, que cuando era pequeña estaba lleno de vida y de comercios, y donde actualmente residen cerca de 40 personas. AP dice que la despoblación «es una terrible realidad. No se queda la gente». En su opinión, falta cobertura en muchos servicios y, además, uno de los problemas principales es la vivienda. Defiende que el hecho de que muchos de los pisos estén en venta y no en alquiler, dificulta que la gente pueda tomar la decisión de vivir en un pueblo. Esto sumado a que muchas de las casas están viejas y necesitan una inversión en reformas.

Varias de las mujeres navarras entrevistadas afirman que hay que analizar la despoblación desde el punto de vista del género. Éstas creen que es necesario que las mujeres tengan independencia económica y que la mejor manera de lograrlo es teniendo un empleo fuera del negocio familiar. Sin embargo, ven dificultades en conseguirlo, ya que la mayoría de los trabajos dirigidos a los roles de mujeres están ocupados. Sin esto, $\mathrm{MO}$ ha visto como en algunas familias los hombres trabajaban en el pueblo y las mujeres en la ciudad y al final la familia entera ha terminado yéndose del pueblo. MC, agricultora y ganadera, ve diferencias en el sector entre hombres y mujeres. Por un lado, menciona que las herramientas están pensadas para ser trabajadas por una persona con mucha fuerza. Por otro lado, también menciona el tema de la seguridad social, a la que no estaba dada de alta en sus primeros años ejerciendo en la profesión, aunque su compañero sí lo estaba.

Sobre el futuro de la economía solidaria en Navarra, parece que la percepción general es positiva y que se percibe como una oportunidad tanto para la agricultura como para la sociedad en su conjunto. En el caso de los Pirineos, en la conversación sale la preocupación por el tema del turismo en el valle. JA afirma que hay que impulsar la economía del primer sector para poder alejarse de la dependencia que está creando el sector turismo en el valle. BU opina que es necesario un cambio en el sistema económico y que en los pueblos esto se puede dar con más facilidad creando coopera- 
tivas y producciones pequeñas. Defiende que hay que respetar los tiempos de la naturaleza, porque «sin nosotras la naturaleza vive, pero nosotras no podemos vivir sin la naturaleza».

En el tema de las instituciones, ninguna de las entrevistadas, aunque se ha preguntado, ha mencionado una política pública que les haya parecido de verdad de ayuda, a excepción de MU que menciona que les llega alguna ayuda desde Europa, aunque critica la forma de actuar de los/las técnicos/ as de Navarra, sintiendo más que una ayuda, una presión por su parte. En general, el sentimiento hacia las instituciones parece ser de rechazo. JA desde su ayuntamiento cree en relaciones más horizontales, ella más que alcaldesa se siente coordinadora. En instituciones más grandes no tiene mucha confianza, y cree que hay que romper con esa relación de poder que tienen las administraciones. Denuncia la falta de políticas personalizadas a las necesidades de cada valle y la poca ayuda que hace tener una ley para toda Navarra por igual. Varias reclaman también ayuda en los temas de acceso a las tierras y a la vivienda.

En el tema de la administración otro de los temas estrella es el de la burocracia y los papeles. Según ML, muchas veces se pierden en los papeles. La gran carga de papeleo que requiere la administración se une con el desconocimiento del tema en el personal al servicio de los departamentos que llevan el medio rural

El Gobierno de Navarra está formado por personas que desconocen este medio. Por lo mismo que son reflejo de la sociedad y que también desconoce. $Y$ luego respecto a las ayudas en el ecológico y eso siempre estamos llenos de burocracia y de incomprensión y todos los años estamos haciendo reclamaciones. Cosas que no tienen nada que ver con la realidad y con la ecología. Por ejemplo, tenemos tierras que siembras un año y duran 5 de producción. Entonces ellos como ven que no estás haciendo "nada» se lo toman como que ya no estás haciendo actividad agrícola y te quitan la ayuda, no entienden, no conocen. Es mucho más profundo el tema que venir a sacar una foto y decir esta no ha labrado, si no ha labrado lo tiene abandonado, este no produce. Oye a ver. Cuando igual es lo más ecológico y natural que puedes hacer para la tierra. Mira por favor lo que hago, pero miralo de verdad.

Varias mencionan que al empezar con su producción desde la administración se les exigía asistir a ciertos cursos sobre agricultura y ganadería. Sin embargo, poco tenían que ver con producción ecológica. Por últimos, coinciden en la necesidad de hacer políticas públicas con perspectiva de género en el tema de la despoblación, creando oportunidades de empleo y tratando la desigual distribución de las tareas de cuidados desde las administraciones. También mencionan de forma generalizada, la necesidad de ofrecer servicios públicos mínimos en las zonas en las que no hay. 


\section{Conclusiones}

La despoblación en Navarra es una realidad. El ritmo al que se están vaciando las zonas rurales y la medida en la que la población emigra a Pamplona y ciudades grandes es cada vez mayor. Además, estas zonas rurales de Navarra cada vez albergan a menos mujeres, y sobre todo, menos mujeres en edad de trabajar. Si se quiere acabar con la despoblación en $\mathrm{Na}-$ varra hay que analizar el porqué. En muchos de los artículos científicos, entrevistas y noticias sobre el tema de la despoblación, si no en todos, se menciona la importancia de hablar específicamente de la situación de las mujeres rurales. Sin embargo, muchos de ellos lo mencionan y no le dedican más que un breve apartado.

La economía solidaria parece calar con los principios que las mujeres entrevistadas reivindican, con preocupación por la naturaleza, por el patrimonio cultural, la diversidad, la vida, en definitiva. La puesta en práctica de sus iniciativas de ESS se ve con dificultades. No obstante, parece que también se considera una oportunidad de cara al futuro. Parece que la población cada vez está más concienciada con el entorno y las personas productoras, y hasta puede que la situación del COVID-19 haya servido de reflexión en este sentido. Sorprende que muchas de las mujeres entrevistadas no sepan que pertenecen a un sector llamado economía solidaria. No muchas conocían REAS y la mayoría no pertenece a ninguna red «oficial».

Las políticas públicas llevadas a cabo en las últimas décadas, han marcado Pamplona como el epicentro de todo. En las dificultades para vivir en las zonas rurales predomina la falta de servicios, como servicios de cuidados, de ocio, de educación formal. En la práctica, muchas de las entrevistadas tuvieron que ir a vivir a Pamplona u otras grandes ciudades para continuar con sus estudios. En las zonas donde hay una buena comunicación por carreteras o conexión con pueblos cercanos, donde no necesiten ir a la ciudad para satisfacer ninguna de sus necesidades, ni siquiera de ocio, no se nota tanto la despoblación. La cuestión no parece ser sólo satisfacer necesidades básicas, sino que las mujeres también piden servicios que hagan atractivo vivir en el pueblo, como ofertas de ocio, de deporte, de cultura, de actividades al aire libre...

Para ello, parece ser determinante conseguir un trabajo en el pueblo. Sin embargo, el mercado de trabajo remunerado se presenta con grandes diferencias entre hombres y mujeres en las zonas rurales también. Las tasas de actividad y de empleo son menores en mujeres que en hombres. Pero, además, las diferencias entre mujeres rurales y urbanas en tasas de actividad y empleo son significativamente mayores que en el caso de los hombres, siendo las tasas más bajas las de las mujeres rurales. Lo que supone que las mujeres navarras en zonas rurales sufren una doble discriminación, una 
por ser mujeres y otra por ser rurales. Es por esto que parece que las iniciativas de economía solidaria se presentan como una gran oportunidad de emprender para estas mujeres rurales. Esto les permite tener independencia económica y poder dedicar su tiempo a un proyecto profesional que al final se convierte en personal y concuerda con los valores de vivir en el pueblo. No es de extrañar que, estas iniciativas se estén asociando a la tendencia a volver a vivir en pueblos, es decir, una nueva ruralización. Esto se ve reflejado en las entrevistas, donde muchas de las mujeres tienen origen urbano, pero han decido ir a vivir a zonas rurales.

El ser partícipes y dueñas de estas iniciativas no solo les ha proporcionado una alta calidad de vida, sino que, en sus palabras, también les ha ayudado a poder conciliar su vida laboral con su vida familiar. No hay que olvidar que las zonas rurales se caracterizan a menudo por la preservación de la cultura tradicional. Eso se mantiene en los valles de Navarra. Estas ideas tradicionales pesan en los hombros de las mujeres que tienen que cumplir con lo que la sociedad y sus familias esperan de ellas. Entre otras, el tema de los cuidados. Este parece ser uno de los temas más destacados en el día a día para las mujeres rurales. La corresponsabilidad de los trabajos de cuidados todavía no se ve reflejada en una igual distribución de estas tareas en hogares rurales de Navarra.

El problema de la desigual distribución de las tareas se ve incrementado al hablar de mujeres rurales que se dedican al sector primario. La línea entre el trabajo doméstico y el remunerado es muy fina cuando la empresa es familiar y hay un solo titular o propietario. Esto se reafirma con los datos de afiliación a la seguridad social y en las entrevistas personales. Cuando no hay dinero para realizar dos altas en la seguridad social, a menudo solo se registra el hombre. Posteriormente, esto tiene como consecuencia que las mujeres que se han dedicado a trabajar de forma invisible, no tienen derecho a prestaciones. Sería interesante involucrar a toda la sociedad en esta lucha, y no sólo a mujeres u organizaciones y colectivos organizados que se dedican a ello.

La lucha contra la desigualdad estructural es o debería ser responsabilidad de los gobiernos. Sin embargo, no parecen estar ayudando mucho. En las entrevistas ha quedado bastante claro que lo que estas mujeres opinan es que es un sistema demasiado vertical. No esperan ninguna ayuda de la administración, al menos, no la han visto hasta el momento. Además, no ven coherente que las decisiones se tomen desde un gobierno central, aprobando leyes que son iguales para toda la provincia, en vez de adaptar las políticas a las necesidades de cada zona. Navarra es muy diversa y las condiciones de una zona no tienen nada que ver con las de otra. Además, existe una desproporcionada burocracia que no facilita la comunicación con la gente. De hecho, la sensación generalizada es que más que ser 
un apoyo, la administración a veces ejerce de obstáculo, y no se paran a escuchar a la gente.

Se reivindica la necesidad de implantar un estilo de gobernanza mucho más horizontal, una política que vaya más desde abajo hacia arriba y, además, que la legislación se adapte a cada zona. Esta forma de gobernar, además, concuerda con los principios de la economía solidaria. En realidad, modelo que parece ser efectivo en el impulso de empleo, de bienestar y de desarrollo local. Es esencial que el freno a la despoblación venga con medidas que promuevan una vía alternativa, sostenible, feminista y ecologista. Se mencionan las cooperativas como posible herramienta de cambio y se recalcan las sinergias que nacen del trabajo colectivo y comunitario y la necesidad de crear redes entre las distintas iniciativas. En pueblos pequeńos donde el trabajo comunitario prevalece, las redes entre las pequeńas empresas que operan son clave no solo para su propia supervivencia, sino también para el desarrollo de los pueblos, de la sociedad y de las relaciones entre las personas. La economía solidaria como motor que impulse el desarrollo local, parece una muy buena herramienta.

En definitiva, las zonas rurales se presentan como una oportunidad de cambio en el sistema, de preservar valores como el cuidado de la tierra, de la naturaleza y también de la salud de las personas, tanto física como psicológica. No podemos dejar que los pueblos se vacíen. La economía solidaria y los valores comunitarios deben ser la herramienta. Creando desde lo individual, un movimiento colectivo, que respetando a las personas y a la naturaleza ponga en el centro a la vida, a la cultura, a vivir despacio, y a vivir conscientes de las consecuencias de nuestros actos. El impulso tiene que ser feminista, y garantizar la igualdad de oportunidades y la igualdad de libertad para mujeres y para hombres. En este proceso, el apoyo y la voluntad real institucional son imprescindibles, y para ello, todo lo que se pueda hacer que reivindique la protección de nuestra tierra, de nuestra cultura y de nuestros cuerpos, es vital.

\section{Bibliografía}

Álvarez, Santiago (2010). Potencialidades y desafíos de la economía solidaria, $P a$ peles de relaciones ecosociales y cambio global, 110 .

Arias Ramírez, Loreto Patricia \& Cid Aguayo, Beatriz Eugenia (2019). La Economía Solidaria en la politización del trabajo escondido de las mujeres. Revista Estudos Feministas, 27(2). DOI: 10.1590/1806-9584-2019v27n254486

Baylina, Mireia (2019). La mujer como eje vertebrador de la nueva ruralidad. Un estado de la cuestión. Perspectives on rural development. Recuperado 9 febrero, 2020, de http://siba-ese.unisalento.it/index.php/prd/article/ view/21522/18251 
Baylina, Mireia \& Berg, Nina Gunnerud (2010). Selling the Countryside: Representations of Rurality in Norway and Spain. European Urban and Regional Studies, 17(3), (pp. 277-292).

Baylina, Mireia, Garcia, Maria Dolores., Porto, Anamaria., Salamaña, Isabel, \& Villarino, Montserrat (2015). Formación de las mujeres, empoderamiento e innovación rural. Boletín de la Asociación de Geógrafos Españoles. (68) doi: 10.21138/bage. 1867

Baylina, Mireia, Garcia, Maria Dolores, Porto, Anamaria, Monsteiro, Maria Josefa, Salamaña, Isabel, \& Villarino, Montserat (2019). Género e innovación en los nuevos procesos de re-ruralización en España. Finisterra. (110) pags 75-91. doi: 10.18055/Finis16053.

Baylina, Mireia, \& Salamaña, Isabel (2006). El lugar del género en la geografía rural. Boletín de la Asociación de Geógrafos Españoles. (41) (pp. 99-112).

Benería, Lourdes (1999) El debate inconcluso sobre el trabajo no remunerado. Revista Internacional del Trabajo 118, 3.

Boletín Oficial de Navarra (2019). Disponible en: https://bon.navarra.es/es/anuncio/-/texto/2019/42/52/

Bosch, Anna, Carrasco, Cristina, \& Grau, Elena (2005). Verde que te quiero violeta. Encuentros y desencuentros entre feminismo y ecologismo. Ponencia presentada en IX Jornadas de Economía Crítica, Universidad Complutense de Madrid, 25-27 de Marzo de 2004, http://www.ucm.es/info/ec/index9.htm

Boserup, Ester (1970). Woman's role in economic development. Nueva York, St. Martin's Press.

Bryant, Lia \& Pini, Barbara (2011). Gender and Rurality. London:Routledge.

Camarero, Luis (coord.) (2006). El trabajo desvelado. Trayectorias ocupacionales de las mujeres rurales en España. Madrid: Instituto de la Mujer. 190p.

Camarero, Luis (2008). Invisibles y móviles: trayectorias de ocupación de las mujeres rurales en Espańa. Revista de Estudios sobre Despoblamiento y Desarrollo Rural 7:9-33.

Camarero, Luis. (2013). Espacios Rurales, ¿Crisis sistémica o brotes verdes? Entrevista con Luis Camarero [Rural spaces, Crisis or green shoots?. Interview with Luis Camarero]. Encrucijadas. Revista critica de Ciencias Sociales, 6 (pp. 6-17).

Camarero, Luis, \& Sampedro, Rosario (2008). ¿Por qué se van las mujeres? El "continuum» de ruralidad como hipótesis explicativa de la masculización rural, Revista Española de investigaciones sociológicas (124) (pp. 73-105).

Carrasco, Cristina (2014). Economía, trabajos y sostenibilidad de la vida. Sostenibilidad de la vida, REAS Euskadi.

Carrasco, Cristina, Alabart, Anna, Domínguez, Márius, \& Mayordomo, Maribel (2001). Hacia una nueva metodología para el estudio del trabajo: propuesta para una EPA alternativa. Tiempos, trabajos y género.(pp. 211-232 ).

Chulvi Ferriols, Berta (1999). Trabajar en un medio masculino y rural. Ruralia, n. 3.

Comunidades Europeas (2002): «La mujer en la agricultura». 
Clout, Hugh (1997). Others in the rural: leisure practices and geographical knowledge. 189-229 en Revealing rural 'others': representation, power and identity in the British countryside, editado por P. Milbourne. London: Pinter.

Comisión Europea (1999). Estrategia Territorial Europea. Disponible en: https:// ec.europa.eu/regional_policy/sources/docoffic/official/reports/pdf/sum_es.pdf

Consejo de Europa (1983). Carta Europea de Ordenación al Territorio. Disponible en: https://www.uco.es/ - gt1 tomam/master/ot/cartaeuropea1983.pdf

Departamento de Cohesión territorial (2019). Gobierno de Navarra. Disponible en: https://www.navarra.es/es/gobierno-de-navarra/departamento-de-cohesion-territorial

El Diario (2020). Navarra expone ante Europa su modelo de lucha contra la despoblación mediante la Banda Ancha. Disponible en: https://www. eldiario.es/navarra/ultima_hora/Navarra-Europa-despoblacion-BandaAncha_0_1033797360.html

Ferber, Marianne A. \& Nelson, Julie (ed.) (1993). Beyond economic man. Feminist Theory and Economics. The University of Chicago Press.

Fernández Aguerri, Maria José (2002). Retos y problemática de la mujer en el ámbito rural. El papel de las agrupaciones de este sector de población en el desarrollo rural. Jornada Temática sobre Politicas de relevo generacional e incorporación de la mujer al mundo rural. Madrid.

Forsberg, Gunnel, \& Stenbacka, Susanne (2013). Mapping Gendered Ruralities. European Countryside, 5 (pp. 1-20).

Gobierno de Navarra (2018). Proyecto de Ley Mapa Local. Disponible en: https:// www.navarra.es/home_es/Actualidad/Sala+de+prensa/Noticias/2018/07/0 4/ proyecto+ley+mapa+local.htm

González Regidor, Jesús (coord.) (2008). Desarrollo rural sostenible: un nuevo desafío. Ministerio de Medio Ambiente y Medio Rural y Marino. Madrid.

Gualda, Estrella, \& Ruiz, Marta (2004). Migración femenina de Europa del Este y mercado de trabajo agrícola en la provincia de Huelva, España. Migraciones Internacionales, 2 (4), (pp. 36-65).

Hedberg, Charlotta, \& Carmo, Renato M. (Eds.) (2012). Translocal Ruralism. Dordrecht: Springer.

Herrero, Yayo (2013). Miradas ecofeministas para transitar a un mundo justo y sostenible. Revista de economía critica. (16), (pp. 278-307). ISSN 1696-0866.

Herrero, Yayo (2014). Perspectivas ecofeministas para la construcción de una economía compatible con una vida buena. Sostenibilidad de la vida, REAS Euskadi.

Herrero, Yayo (2020). Disponible en: https://www.youtube.com/ watch?v=BoDObApEcWA

Herrero, Yayo, \& Pascual, Marta (2010). Ecofeminismo, una propuesta para repensar el presente y construir el futuro. Boletin ECOS (10).

Himmelweit, Susan (2002). Making Visible the Hidden Economy: The Case for Gender-Impact Analysis of Economic Policy. Feminist Economics, 8(1), (pp. 49-70). 
Jubeto, Yolanda, \& Larrañaga, Mertxe (2014). La economía será solidaria si es feminista. Aportaciones de la economía feminista a la construcción de una economía solidaria. Sostenibilidad de la vida, REAS Euskadi.

Ley Foral 4/2019, de 4 de febrero, para la reforma de la administración local de Navarra. Boletín Oficial de Navarra, núm. 25, del 6 de febrero de 2019. Recuperado de http://www.lexnavarra.navarra.es/detalle.asp? $r=51129$

Libro Blanco de la Agricultura y el Desarrollo Rural (2003). El papel de la juventud y la mujer en la agricultura y el medio rural. Cap. 3 de La agricultura del futuro: un compromiso de todos, publicado por el Ministerio de Agricultura, Pesca y Alimentación, www.libroblancoagricultura.com

Little, Jo (1999). Otherness, representation and the cultural construction of rurality. Progress in Human Geography, 23(3), (pp. 437-442).

Little, Jo (2015). The Development of Feminist Perspectives in Rural Gender Issues. In B. Pini, B. Brandth, J. Little (Eds.), Feminisms and Ruralities (pp. 107118). Lanham: Lexington books.

Maggliano, María José (2009). Migración, género y desigualdad social. La migración de mujeres bolivarianas hacia Argentina. Universidad Nacional de Córdoba, Argentina. Estudos Feministas, Florianópolis, 17(2): 344.

Mattahei, Julia (2010). Más allá del hombre económico: crisis económica, economía feminista y la economía solidaria. Cayapa. Revista Venezolana de Economía Social, vol. 10, núm. 19, enero-junio, 2010, (pp. 65-80), Universidad de los Andes, Venezuela.

Millán Jiménez, María Ascensión (2002). Las mujeres en la agricultura y la ganadería. Jornada Temática sobre Políticas de relevo generacional e incorporación de la mujer al mundo rural. Madrid. Noviembre.

Ministerio de medio ambiente y medio rural y marino (2011). Diagnóstico de la Igualdad de Género en el Medio Rural, Madrid.

Monllor, Neus, \& Fuller, Anthony (2016). Newcomers to farming: towards a new rurality in Europe. Documents d'Anàlisi Geogràfica, 62(3), (pp. 553-567).

Mozas Moral, Adoración, \& Bernal Jurado, Enrique (2006). Desarrollo territorial y economía social. CIRIEC-España, Revista de Economía Pública, Social y Cooperativa, 55, agosto, 2006, (pp. 125-140).

Mugarik Gabe Nafarroa (2017). Mujeres y productoras y soberanía alimentaria en Navarra: una mirada desde el género.

Muñiz Espada, María Ester (2002). Relaciones entre las experiencias agrarias y el mundo rural a través de la actividad de las mujeres. Jornada Temática sobre Políticas de relevo generacional e incorporación de la mujer al mundo rural. Madrid.

Nafarroako Estatistika Erakundea / Instituto Navarro de Estadística

Noticias de Navarra (2019). El Gobierno de Navarra acuerda crear la comisión de lucha contra la despoblación. Disponible en: https://www.navarra.es/es/ noticias/2019/11/13/el-gobierno-de-navarra-acuerda-crear-la-comision-de-lucha-contra-la-despoblacion

Observatorio de realidad social Navarra (2020). Desigualdades territoriales de Navarra. Disponible en: https://bit.ly/2UpyeQG 
Oso Casas, Laura (2008). La inmigración en la sociedad española: una radiografía multidisciplinar. ISBN 978-84-7290-407-1 (pp. 561-586).

Paniagua, Ángel (2007). Los flecos y lo relevante en los estudios rurales. AGER: Revista de estudios sobre despoblación y desarrollo rural, 6 (pp. 183-192).

Parlamento de Navarra (2005) Estrategia Territorial Navarra. Disponible en: https:/www.navarra.es/home_es/Temas/Territorio/Urbanismo/Instrumentos/ Inst rumentos+OT/ETN/DEFAULT.htm

Pérez Orozco, Amaia (2006). Perspectivas feministas en torno a la economía: El caso de los cuidados. Madrid: Consejo Económico y Social.

Pérez Díaz, Victor (1971). Emigración y cambio social: procesos migratorios y vida social en Castilla. Barcelona: Ariel.

Pérez Soriano, Josep (2013). Mujeres de pueblo y desarraigo en la ruralidad valenciana. Universitat de Valencia. ISSN 2174-6753, (6) (pp. 101-116).

Pini, Barbara, \& Leach, Belinda (2011). Transformation of class and gender in the globalised countryside: An introduction. In B. Pini \& Leach, B. (Eds.), Reshaping gender and class in rural space (pp.1-24). Aldershot: Ashgate.

Power, Marilyn (2004). Social Provisioning as a Starting Point for Economic Theory: A Feminist Political Economic Methodology, Feminist Economics, 10(3), (pp. 3-19).

Rico González, Margarita, \& Gómez García, Jesús Ma (2011). Economía social e igualdad de oportunidades en el ámbito rural. un análisis aplicado a la comunidad autónoma de castilla y león. revesco. Revista de Estudios Cooperativos, (105),85-114 [fecha de Consulta 9 de Febrero de 2020]. ISSN: 1135-6618. Disponible en: https://www.redalyc.org/articulo.oa?id=367/36718802005

Salazar, Cecilia (2014). La economía social y solidaria: Un diálogo necesario entre tradición y modernidad. Sostenibilidad de la vida, REAS Euskadi.

Sampedro, Rosario (1996). Género y ruralidad. Las mujeres ante el reto de la desagrarización. Madrid: Ministerio de Trabajo y Asuntos Sociales. 544 p.

Solé, Carlota (2008). Las trayectorias sociales de las mujeres inmigrantes no comunitarias en España. Factores explicativos de la diversificación de la movilidad laboral intrageneracional. Informe disponible en: http://www.inmujer.migualdad.es/ mujer/mujeres/estud_inves/798.pdf

Soronellas, Montserrat, Bodoque, Yolanda, Roquer, Santiago, \& Torrens, Ramona (2013). Inmigrar a la Cataluña rural. Contextos de ruralidad y migraciones de mujeres extranjeras hacia pequeños municipios. Revista de estudios sobre despoblación y desarrollo rural. DOI: 10.4422/ager.2014.01

Taboadela, Obdulia, Maril, María, \& Lamela, Carmen (2018). La superdiversidad migratoria en el medio rural: Odemira, Alentejo, un estudio de caso [Migratory superdiversity in rural areas: Odemira, Alentejo, a study case]. Finisterra - Revista Portuguesa de Geografia, LIII (107), (pp. 87-105).

Viladomiu, Lourdes, \& Rosell, Jordi (2016). Nova ruralitat a Catalunya a les últimes dècades: diversificació emprenedoria i ocupació [New rurality in Catalonia during last decades: diversification, entrepreneurship and ocupation]. Documents d'Anàlisi Geogràfica, 62(3), 553-567. 
Wood, Cynthia (1997). The First World / Third Party Criterion, A Feminist Critique of Production Boundaries in Economics. Feminist Economics, 3 (3), (pp. 47-68).

Woods, Michael (2016). International Migration, Agency and Regional Development in Rural Europe. Documents d'Anàlisi Geogràfica, 62(3), (pp. 569-593). 